\title{
Time Course and Nerve Growth Factor Dependence of Inflammation-Induced Alterations in Electrophysiological Membrane Properties in Nociceptive Primary Afferent Neurons
}

\author{
Laiche Djouhri, ${ }^{1}$ Dave Dawbarn, ${ }^{2}$ Alan Robertson, ${ }^{2}$ Richard Newton, ${ }^{1}$ and Sally N. Lawson ${ }^{1}$ \\ ${ }^{1}$ Department of Physiology, University of Bristol, Medical School, University Walk, Bristol BS8 TD, United Kingdom, and \\ 2University Research Center for Neuroendocrinology, Bristol Royal Infirmary, Bristol BS2 8HW, United Kingdom
}

Novel findings of changes in nociceptive dorsal root ganglion (DRG) neurons during hindlimb inflammation induced by complete Freund's adjuvant (CFA) injections in the hindpaw and hindleg are reported. These include increased maximum fiber following frequency in nociceptive $\mathrm{C}$ - and $\mathrm{A} \delta$-fiber units by 2.7 and 3 times, respectively, and increased incidence of ongoing (spontaneous) activity by 3.3 times (to $54 \%$ ) and 2.4 times (to $27 \%$ ), respectively. These changes and the CFA-induced changes in somatic action potential (AP) configuration in nociceptive neurons (Djouhri and Lawson, 1999) were incomplete $24 \mathrm{hr}$ after CFA. The nerve growth factor (NGF) dependence of the inflammation-induced changes was examined by injecting a synthetic NGF sequestering protein [tyrosine receptor kinase $A$ lg2 (trkA lg2)] with CFA and subsequently into the CFA injection sites. NGF sequestration prevented some CFA-induced changes in nociceptive neurons including: the increased fiber following frequency $(C$ and $A \delta)$, the increased proportions of units with ongoing activity $(C$ and $A \delta)$, the decreased AP duration $(C$ and $A \delta)$, but not the decreased afterhyperpolarization (AHP) durations (C, $\mathrm{A} \delta$, and $\mathrm{A} \alpha / \beta)$ (Djouhri and Lawson, 1999). $\mathrm{AP}$ variables of nociceptive units with spontaneous activity were examined.

The time course of electrophysiological changes in nociceptive units is consistent with processes involving altered protein expression and/or retrograde transport of factors. These results (1) implicate NGF in regulating inflammation-induced decreases in AP duration and in increases in firing rate and spontaneous activity but not in decreases in AHP duration and (2) suggest clinical advantages of reducing NGF in some inflammatory pain states.

Key words: nociceptive neurons; DRG; hyperalgesia; NGF; firing rate; spontaneous activity
Inflammation is accompanied by hyperalgesia and allodynia. The underlying neuronal mechanisms are not fully understood, but short-term (hours) changes at more than one level of the nociceptive pathway occur, including sensitization of peripheral terminals and of central pathways (for review, see Millan, 1999). However, it is clear that longer term (days) changes in the electrical properties of the entire primary afferent neuron also occur during inflammation. These include decreased durations both of somatic action potentials (APs) in nociceptive C- and $\mathrm{A} \delta$-fiber units and of afterhyperpolarizations (AHPs) in nociceptive $\mathrm{A} \delta$ and $\mathrm{A} \alpha / \beta$-fiber neurons (Djouhri and Lawson, 1999). The time course of these changes was not known.

Nerve growth factor (NGF) is upregulated in inflamed tissues and transported back to the dorsal root ganglia (DRGs) (Woolf et al., 1994). NGF is implicated in mediating inflammatory hyperalgesia because (1) administration of NGF leads to hyperalgesia in adult rats (Lewin et al., 1993; Woolf et al., 1994) and in humans (Petty et al., 1994; Dyck et al., 1997), (2) it sensitizes nociceptive neurons (Dmitrieva and McMahon, 1996; Rueff and Mendell, 1996), (3) transgenic mice that overexpress NGF in skin are hyperalgesic (Davis et al., 1993), and (4) neutralization of endogenous NGF blocks inflammation-induced hyperalgesia and sensi-

\footnotetext{
Received April 19, 2001; revised July 27, 2001; accepted Sept. 5, 2001.

This work was supported by a Wellcome Trust United Kingdom grant to S.N.L. Alan Robertson was supported by a Sigmund Gestetner Research Fellowship.

Correspondence should be addressed to Dr. Laiche Djouhri, Department of Physiology, University of Bristol, Medical School, University Walk, Bristol BS8 1TD, UK. E-mail: l.djouhri@bristol.ac.uk.

Copyright (ㄷ) 2001 Society for Neuroscience $\quad 0270-6474 / 01 / 218722-12 \$ 15.00 / 0$
}

tization (Woolf et al., 1994; McMahon et al., 1995; Koltzenburg et al., 1999). Because inflammatory hyperalgesia is NGFdependent, sequestration of NGF should reverse membrane changes that contribute to it.

Previous in vivo studies found NGF or anti-NGF treatments to cause changes in duration of the AP but not the AHP in A-fiber nociceptive DRG neurons in the rat (Ritter and Mendell, 1992). Evidence is accumulating that NGF may exert such effects by causing changes in ionic currents (such as $\mathrm{Na}^{+}$and $\mathrm{K}^{+}$currents) responsible for AP electrogenesis in DRG neurons (Oyelese et al., 1997; Fjell et al., 1999a; Everill and Kocsis, 2000). Together these findings suggest that the inflammation-induced changes in the somatic AP configuration in nociceptive neurons (Djouhri and Lawson, 1999) may result from actions of NGF. The lack of selective trkA receptor antagonists and the cross-reactivity with other neurotrophins of some previously used neutralizing antibodies (Murphy et al., 1993) led us to use an NGF sequestering molecule that blocks actions of NGF via sequestration both in vivo and in vitro (Holden et al., 1997; Robertson et al., 2001). It is smaller than that used previously by McMahon et al. (1995).

We therefore examined the time course and NGF dependence of the complete Freund's adjuvant (CFA)-induced decreases in AP and AHP durations. We also examined whether these changes in nociceptive neurons during inflammation were accompanied by increased maximum fiber firing frequencies and/or increased incidence of spontaneous firing, and if so whether these latter changes were NGF-dependent.

A brief report of these studies has been published in abstract form (Djouhri et al., 1999). Some AP measurements from control 
and CFA 2-4 d animals (Fig. 3) were included in Djouhri and Lawson (1999). The increased data and greater number of time points enable novel time course studies of CFA effects and novel comparison with NGF sequestration data.

\section{MATERIALS AND METHODS}

\section{Sequestration of endogenous NGF with the trk $\mathrm{Ag}_{2}$ domain}

NGF exerts its biological actions by stimulating the dimerization of two transmembrane trkA receptors. The extracellular domain of trkA comprises three tandem leucine-rich motifs flanked by two cysteine cluster regions followed by two Ig-like domains. Mutagenesis studies have shown that the Ig-like domains are important for the binding of neurotrophins (Perez et al., 1995; Urfer et al., 1995). Recombinant Ig-like domains when produced in Escherichia coli have been shown to bind NGF with a $K_{\mathrm{d}}$ similar to the wild-type membrane-bound receptor and to block the actions of NGF via sequestration both in vitro and in vivo (Holden et al., 1997). The NGF sequestering molecule (trkA-IgG) used previously by McMahon et al. (1995) used the trkA extracellular region for NGF binding. However, more recently the structure of the second Ig-like domain (amino acids 285-413) was determined on its own (Ultsch et al., 1999; Robertson et al., 2001), bound to NGF (Ultsch et al., 1999; Wiesmann et al., 1999), and found to bind to NGF with an affinity similar to that of the entire extracellular domain. That is, all the NGF binding was localized to this 285-413 trkAIg2 domain. This domain, when crystallized on its own, appeared as a strand-swapped dimer consisting of two $\beta$ sheets formed from strands ABED and CFG, respectively, with a disulphide bond linking strands $\mathrm{B}$ and $\mathrm{E}$; the structure of the NGFTrkAIg2 domain complex showed that one NGF binds to two trkAIg2 domains (Robertson et al., 2001). This NGF binding domain (NBD) (amino acids 285-413 of trkAIg2) is abbreviated as "NBD" from this point on.

\section{Treatment with CFA and NBD}

Four groups of young female Dunkin Hartley guinea pigs (weight 180$300 \mathrm{gm}$ ) were used. Group 1 had no CFA treatment (normal). In group 2 , a unilateral hindlimb inflammation was induced on day 0 , under anesthesia with $4 \%$ halothane, by two intradermal injections of a $1 \mathrm{mg} / \mathrm{ml}$ solution of CFA. The first $(75 \mu \mathrm{l})$ was into the plantar surface of the left hindpaw, and the second (also $75 \mu \mathrm{l}$ ) was into the lateral region of the left knee. These injections were given $1 \mathrm{~d}$ (CFA1D), $2 \mathrm{~d}$ (CFA2D), or $4 \mathrm{~d}$ (CFA4D) before the electrophysiological recordings. Group 3 animals had an injection of $75 \mu \mathrm{l}$ of CFA solution mixed with a $30 \mu \mathrm{l}(15 \mu \mathrm{g} / \mathrm{ml})$ solution of NBD previously dissolved in PBS and $10 \%$ glycerol (v/v) into each of the same two sites used for group 2 on day 0 , plus on each of days 1,2 , and 3 an injection of $30 \mu \mathrm{l}$ of the NBD solution in each of the same two sites. All the injections were within the cutaneous receptive fields of L6 and S1 DRGs in the guinea pig. Group 4 animals were injected with CFA exactly as group 2 and used for behavioral tests (see below).

\section{Behavioral studies}

Behavioral studies were conducted on guinea pigs in which unilateral hindlimb inflammation had been induced with CFA (group 4) to ascertain whether the development of inflammatory hypersensitivity after CFA injection was similar to that previously reported for the rat. Thermal sensitivity of the hindpaws was measured using a focused thermal stimulator system (Hargreaves et al., 1988). Female guinea pigs (200-240 $\mathrm{gm} ; n=6$ ) were placed in clear perspex chambers above a glass floor and allowed $5 \mathrm{~min}$ to acclimatize to their environment. The radiant heat source was then positioned beneath the plantar surface of the hindpaw, and the latency for foot withdrawal from the onset of stimulation was automatically recorded. The heat stimulation was repeated four times at an interval of $5 \mathrm{~min}$ for each animal, and the average withdrawal latency for each hindpaw calculated. Baseline withdrawal responses for both hindpaws were determined from testing sessions 48, 24, and $1 \mathrm{hr}$ before the injection of one hindpaw with CFA. Withdrawal thresholds were measured $5 \mathrm{hr}$ after injection and then at intervals of $1,2,3,4,5,7,9,11$, and $14 \mathrm{~d}$. Comparisons between ipsilateral and contralateral hindpaw withdrawal latencies at different time points were performed using ANOVA and Bonferroni post hoc testing on selected groups, that is between ipsilateral and contralateral groups at each time point. Paw volume was measured $14 \mathrm{~d}$ after CFA, using a hydroplethismometer (Basile, Ugo, Italy), at which time the volume of the ipsilateral hindpaw $(2.62 \pm 0.09 \mathrm{ml})$ was still significantly greater than that of the contralateral hindpaw $(1.85 \pm 0.06 \mathrm{ml}$; mean $\pm \mathrm{SEM} ; p<0.005)$.

\section{Electrophysiology}

For electrophysiological recordings, animals were anesthetized initially with sodium pentobarbitone $(50 \mathrm{mg} / \mathrm{kg}$, i.p. $)$. Because this produced deep anesthesia that depressed ventilation in guinea pig, a tracheotomy was performed immediately after induction of anesthesia to allow artificial ventilation and continuous monitoring of end-tidal $\mathrm{CO}_{2}$. The left carotid artery was then cannulated to permit intra-arterial injection of drugs. Deep anesthesia (i.e., areflexia, judged by complete absence of limb withdrawal reflex) was maintained thereafter with supplementary doses of anesthetic $(10 \mathrm{mg} / \mathrm{kg}$, i.a.) each hour. In most experiments, the right carotid artery was cannulated to monitor blood pressure. During electrophysiological recording, animals were paralyzed with either gallamine triethiodide (Flaxedil; $2 \mathrm{mg} / \mathrm{kg}$, i.a.) or pancuronium $(0.5 \mathrm{mg} / \mathrm{kg}$, i.a.) accompanied always by an additional dose $(10 \mathrm{mg} / \mathrm{kg}$, i.a.) of the anesthetic at regular intervals. The dose $(10 \mathrm{mg} / \mathrm{kg}$, i.a. $)$ and frequency of administration (every hour) of the supplementary anesthetic was the same before and during paralysis and was sufficient to maintain complete areflexia in the period before paralysis. Blood pressure remained stable throughout the period of paralysis. Core temperature was maintained at $36 \pm 0.5^{\circ} \mathrm{C}$. Details of exposing and stabilizing the DRGs were as described previously (Djouhri and Lawson, 1999).

Intracellular recordings from somata in DRGs were made under liquid paraffin maintained at $30^{\circ} \mathrm{C}$ (range, $\pm 2^{\circ} \mathrm{C}$; mean, $30^{\circ} \mathrm{C}$ ) with glass micropipettes filled with $1 \mathrm{M} \mathrm{KCl}$ (electrode resistance, 50-120 M 2 ), Lucifer yellow $(5 \mathrm{mg} / \mathrm{ml}$ in $0.1 \mathrm{M} \mathrm{LiCl}$ solution; $100-700 \mathrm{M} \Omega$ ) or ethidium bromide ( $6 \mathrm{~mm}$ in $1 \mathrm{M} \mathrm{KCl} ; 60-140 \mathrm{M} \Omega$ ). The dorsal root of the DRG under study was cut close to its entry to the spinal cord and laid over bipolar platinum electrodes that delivered single $0.03 \mathrm{msec}$ (A-fiber) or $0.3 \mathrm{msec}$ (C-fiber) rectangular stimulation pulses, adjusted to twice threshold voltage for A-fiber units and suprathreshold ( $\sim 1.5$ times threshold) for C-fiber units. APs evoked by dorsal root stimulation were recorded on line with a Cambridge Electronic Design (CED, Cambridge, UK) 1401plus interface and SIGAV program and were subsequently analyzed with the SpikeII program (CED). The conduction velocity $(\mathrm{CV})$ of the recorded units was calculated from the latency to the rise of the somatic AP evoked by dorsal root stimulation and the conduction distance between the recording site in the ganglion and the stimulating cathode (typically 4-7 mm). Utilization time was not taken into account in calculating CVs.

\section{Electrophysiological variables measured}

Action potential variables. The AP variables measured are illustrated in Figure 1. For all measurements except following frequency (see below), only units with overshooting APs were included in the analyses. In addition, only those A-fiber cells with a stable membrane potential $\left(E_{\mathrm{m}}\right)$ more negative than $-40 \mathrm{mV}$ were included. Because mean AP and AHP duration to $80 \%\left(\mathrm{AHP}_{80}\right)$ in $\mathrm{C}$-fiber neurons were previously shown to be unaffected by the inclusion of units with $E_{\mathrm{m}}$ values as low as $-30 \mathrm{mV}$ (Djouhri et al., 1998) (see Figs. 3, 4), all C-fiber units with $E_{\mathrm{m}}$ values equal to or more negative than $-35 \mathrm{mV}$ were included.

Following frequency. To examine the hypothesis that inflammationinduced changes in AP configuration in nociceptive neurons reported previously (Djouhri and Lawson, 1999) would lead to faster firing frequencies than normal, the $80 \%$ fiber following frequencies $\left(\mathrm{FFF}_{80 \%}\right)$ of some dorsal root fibers were tested as shown in Figure $1 B-D$. The dorsal roots were stimulated with trains of electrical stimuli at frequencies of $10-500 \mathrm{~Hz}$, and evoked potentials were recorded intracellularly (Fig. $1 B, C)$. The stimulus threshold was established in the same way as for single shock dorsal root stimulation (see above). The duration of the trains was $200 \mathrm{msec}$, and the stimulation frequency was gradually increased from $0.33 \mathrm{~Hz}$ with a short pause of at least $4 \mathrm{sec}$ between trains. As the stimulus frequency was increased, conduction failure of APs occurred as reflected either by absence of APs (Fig. 1C, arrow) and/or by noninvading APs (electrotonic responses) in the soma (small responses in Fig. 1C). In some units (not related to functional properties) three sizes of potential were recorded: full size, approximately half size, and very small (as also reported by Stoney, 1990). The two different sizes of electrotonic response (the half-sized and small responses) appear to 


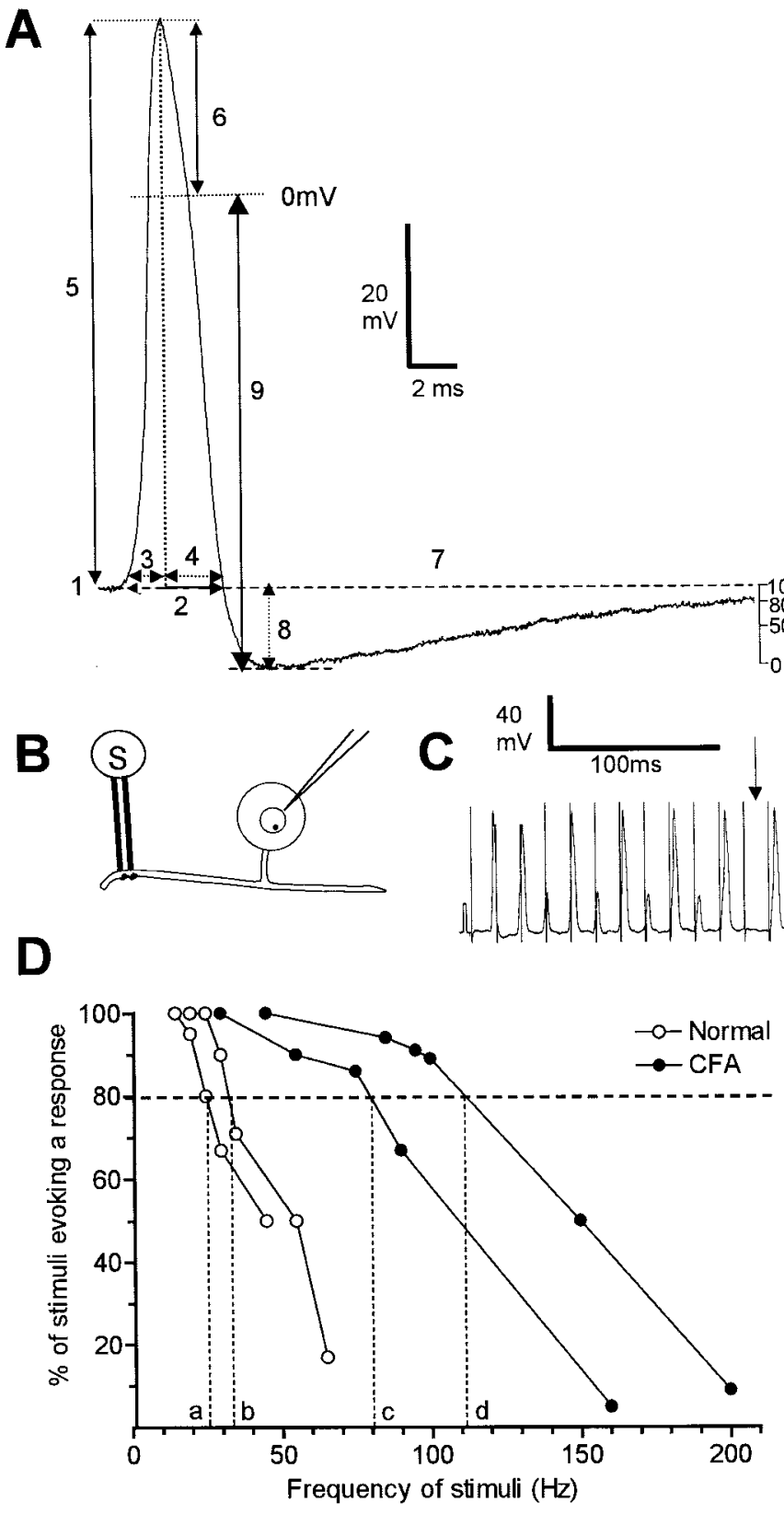

Figure 1. AP variables measured $(A)$ and methods used to evaluate fiber following frequency $(B-D)$. $A$ shows the AP variables measured superimposed on an intracellular AP evoked by a single stimulus of the dorsal root. The variables were: 1 , membrane potential $\left(E_{\mathrm{m}}\right) ; 2$, APDB; 3 , APRT; 4, APFT; and 5, AP height; 6, AP overshoot; 7, AHP duration to $80 \%$ recovery $\left(\mathrm{AHP}_{80}\right) ; 8$, AHP depth measured from $E_{\mathrm{m}}$ (AHP to $E_{\mathrm{m}}$ ); and 9 , AHP depth measured from $0 \mathrm{mV}$ (AHP to 0 ). In addition the MRR and the MRF of the AP were measured from a differential trace of each AP. The trace shown here is from a C-polymodal nociceptive neuron from a normal animal with a dorsal root CV of $0.39 \mathrm{~m} / \mathrm{sec}$ and $E_{\mathrm{m}}$ of 54 $\mathrm{mV} . B-D$ show the experimental set up and methodology of following frequency measurements. $B$, Intracellular recordings were made from the somata of L6 and S1 DRG neurons, and APs were evoked by trains of electrical stimulation $(S)$ to the dorsal root. $C$ shows an example of firing of a $\mathrm{C}$ nociceptive unit $\left(\mathrm{CV}=0.39 \mathrm{~m} / \mathrm{sec} ; E_{\mathrm{m}}=-54 \mathrm{mV}\right)$ to a stimulus train in an untreated animal. Note the electrotonic responses (small potentials), which reflect APs in the fiber, that, having failed to propagate across a site of low safety factor (the T-junction and/or the entrance of the axon into the soma) (see Results for detail), were decrementally conducted into the soma. The absence of any response (arrow) reflects failure of propagation along the dorsal root fiber. $D$, Plots of typical $\mathrm{C}$-fiber nociceptive units, two from untreated animals (open symbols) and indicate that failure could occur at two sites. The most likely are the sites of low safety factor, which are the T-junction and the entrance of the axon into the soma as described by Luscher et al. (1994).

The fiber maximum following frequency was the frequency at which each stimulus resulted in such an electronic response or full AP. When the responses changed from full spikes to no response with increased frequency, the maximum firing frequency in the fiber was assumed to be the same as that in the soma. For each frequency the percentage of stimuli evoking AP or electrotonic response in the soma was plotted against frequency. The frequency at which $80 \%$ of the stimuli were followed by any response (full-sized or electrotonic) was the $\mathrm{FFF}_{80 \%}$ and was read off the $x$-axis, as shown in Figure $1 D$. Similarly, the frequency at which $80 \%$ of the stimuli were followed by a full-sized response was the soma $\mathrm{FF}_{80 \%}$ and was calculated from a graph similar to that in Figure $1 D$.

Spontaneous activity. Spontaneous activity is thought to contribute to abnormal pain behavior in animals and neuropathic pain in humans by sensitizing spinal cord neurons (Nordin et al., 1984). In addition, spontaneous firing of nociceptive neurons is likely to cause spontaneous pain directly. Because spontaneous activity may also be important in pain associated with inflammatory conditions, the presence or absence of ongoing (spontaneous) activity (that is, activity not evoked by electrical or natural search stimuli) in each DRG neuron was noted in all groups of animals.

\section{Sensory receptive properties}

The sensory receptive properties of units were examined with hand-held stimulators and classified as previously described (Lawson et al., 1997; Djouhri and Lawson, 1999). Nociceptive units were identified using noxious mechanical stimuli, including pinch with fine forceps or coarsetoothed forceps, sharp objects (needle), and noxious heat (hot water at $>50^{\circ} \mathrm{C}$ or heated glass rod). They included (1) high-threshold mechanoreceptive units that responded only to strong mechanical stimulation, (2) moderate pressure units that responded weakly to moderate pressure but more vigorously to strong mechanical stimulation, and (3) units that responded to both strong mechanical stimuli and also promptly to a single application of noxious heat. Included in the last category were C polymodal nociceptive units that responded to superficial mechanical stimuli and $\mathrm{C}$ mechano-heat units that responded to deep mechanical stimuli (probable dermal receptive fields) as well as A-fiber mechanoheat units with superficial or dermal receptive fields. Low-threshold mechanoreceptor (LTM) units were identified by their response to nonnoxious stimuli including soft brush, light pressure with a blunt object and with Von Frey hairs, light tap, vibration, and cooling. Unresponsive neurons were those not excited by any of the above non-noxious or noxious stimuli. Specific heat and cooling receptors were not numerous and were not included in this study. All subgroups of nociceptive neurons were clearly recognizable in all three groups of animals.

Animals were killed with an overdose of anesthetic. Experimental procedures complied throughout with United Kingdom Home Office Guidelines.

\section{Statistical analyses}

For the behavioral tests, comparisons between ipsilateral (CFA) and contralateral mean withdrawal latencies at different time points were performed using one-way ANOVA. Paw girth was compared between ipsilateral and contralateral paws with the paired $t$ test (Fig. 2). Electrophysiological data were analyzed as follows: the Kruskall-Wallis test (a nonparametric equivalent of one-way ANOVA) was used to compare the medians of variables in the control group with those 1,2 , or $4 \mathrm{~d}$ after CFA. A nonparametric test (Mann-Whitney $U$ test) was used to compare the medians of these variables $4 \mathrm{~d}$ after CFA with medians from animals that had been treated with CFA and NBD (Figs. 3-5, except C, $\mathrm{F}$, and I). $\chi^{2}$ tests were used to compare the proportions of units showing spontaneous activity in treated and untreated groups (Fig. 5). Levels of significance are indicated on graphs as follows: ${ }^{*} p>0.05$ and $<0.1$;

two from CFA2D animals ( filled symbols). The frequency at which the evoked potentials followed $80 \%$ of the stimuli in the train $\left(\mathrm{FFF}_{80 \%}\right)$ was read off the $x$-axis. 


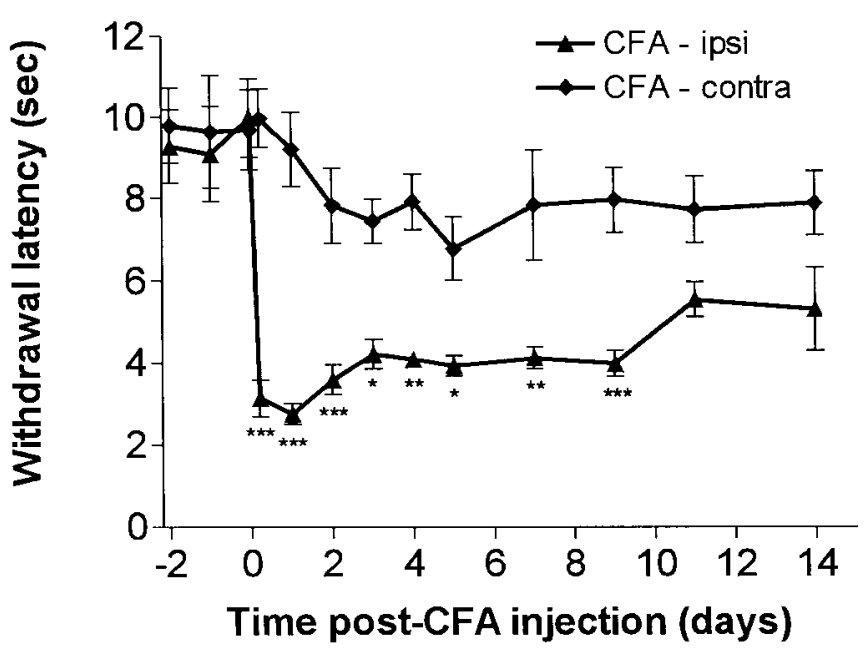

Figure 2. Time course of changes in paw withdrawal latencies after unilateral CFA injection. A clear reduction in the withdrawal response latency to nociceptive heat stimulation was observed in the CFA-injected paw. Comparison of withdrawal latencies of the CFA-injected ipsilateral paw with the noninjected contralateral paw were performed using ANOVA and Bonferroni's post hoc testing on selected groups (that is between means for ipsilateral and contralateral groups at each time point). This revealed a significant reduction within $5 \mathrm{hr}$ after CFA injection that persisted until $9 \mathrm{~d}$ after injection: ${ }^{*} p<0.05 ;{ }^{*} p<0.011$; $* * * p<0.001$.

${ }^{*} p<0.05 ; * * p<0.01-0.001 ; * * * p<0.001$, unless otherwise indicated. Throughout, $p<0.05$ was considered to indicate statistical significance.

\section{RESULTS}

\section{Inflammation and foot size}

As previously reported (Djouhri and Lawson, 1999), CFA treatment produced an area of erythema and edema in the ipsilateral (left) foot and leg. All regions of the leg and foot showed these signs of inflammation. However, the hip did not appear to be inflamed, and units with receptive fields in that region were excluded from the analyses.

Compared with the contralateral (noninjected) right foot, the girth of the ipsilateral (injected) foot measured near the first site of CFA injection in the paw was significantly increased from (contralateral) $26.2 \pm 0.51 \mathrm{~mm}$ to (ipsilateral) $31.3 \pm 0.58 \mathrm{~mm}$ (i.e., by $19.7 \pm 0.9 \%$ ) $2 \mathrm{~d}$ after CFA (mean $\pm \mathrm{SE} ; n=29 ; p<$ 0.0001 ) and from $26.9 \pm 0.73 \mathrm{~mm}$ to $32.6 \pm 0.71 \mathrm{~mm}$ (i.e., by $19.7 \pm 1.4 \%)$ at $4 \mathrm{~d}(n=20 ; p<0.0001)$. In agreement with previous findings that NGF sequestration with an NGFneutralizing molecule (trkA-IgG) did not affect carrageenaninduced inflammation (Koltzenburg et al., 1999), treatment with NBD did not noticeably affect the signs of inflammation (tissue edema and paw girth). Indeed, in animals treated with CFA plus $\mathrm{NBD}$, the mean girth of the ipsilateral foot $(28.6 \pm 0.58 \mathrm{~mm} ; n=$ 9) was still significantly larger (by $20.8 \pm 1.9 \%$; $p<0.0001$ ) than that of the contralateral foot. However, the contralateral foot after CFA plus NBD had a significantly $(p<0.05)$ smaller girth $(23.7 \pm 0.33 \mathrm{~mm} ; n=9)$ than that of the contralateral foot in animals treated with CFA only; this was not attributable to a difference in overall weight of the animals and may therefore result from a systemic effect of the NBD.
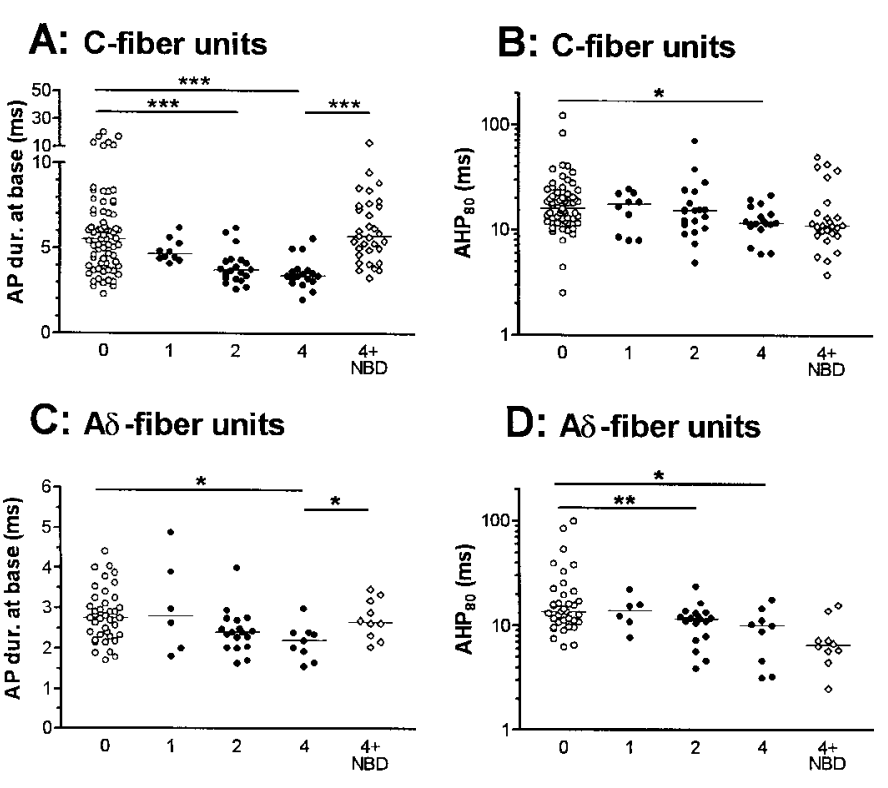

D: A $\delta$-fiber units

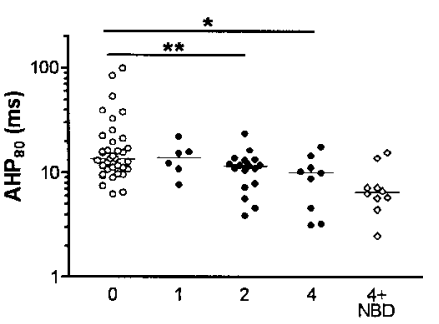

E: A $\alpha / \beta$-fiber units

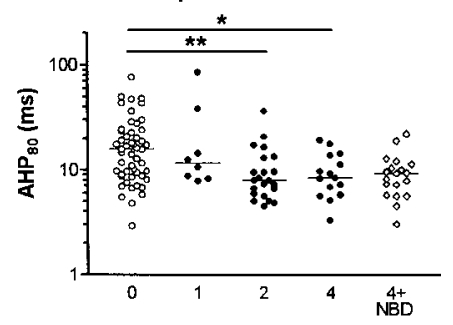

Figure 3. Effects of CFA and of NGF sequestration on AP variables in nociceptive neurons. Scatterplots to show effects in nociceptive neurons on AP and AHP duration where a significant change was found in response to CFA treatment. Each point shows the value for one neuron. For $\mathrm{C}$ fiber neurons AP duration $(A)$ and AHP duration to $80 \%$ recovery $(B)$ are shown, for A $\delta$ units, AP duration $(C)$ and AHP duration $(D)$ are shown, and for $\mathrm{A} \alpha / \beta$ neurons only AHP duration $(E)$ is shown. Statistical comparisons were made with the Kruskal-Wallis test between the $0,1,2$, and 4 columns followed by Dunn's post-test comparing columns 0 and 1, 0 and 2, and 0 and 4 . The 4 (CFA4D) and $4+$ NBD (CFA4D plus NBD) columns were compared with the Mann-Whitney $U$ test to establish if NGF sequestration reversed the changes seen $4 \mathrm{~d}$ after CFA. $P$ values are indicated above the columns as follows: ${ }^{*} p<0.05 ;{ }^{*} p<0.01$ and $* * * p<0.001$.

\section{Behavioral responses to thermal stimulation}

Figure 2 shows that ipsilateral paw withdrawal latencies to noxious radiant heat decreased within $5 \mathrm{hr}$ of CFA injections. The minimum latencies were seen $24 \mathrm{hr}$ after injection. Over the following week, the latencies remained significantly shorter than those for the untreated contralateral paws. Within 2 weeks, paw withdrawal latencies showed a return to near control levels. This time course is very similar to that observed previously after CFA injection in the rat (Woolf et al., 1994; Gould et al., 1998).

\section{Selection and classification of electrophysiological data}

In treated and untreated animals, neurons were classified according to their dorsal root $\mathrm{CVs}$ as $\mathrm{C}, \mathrm{A} \delta$, or $\mathrm{A} \alpha / \beta$ units with $\mathrm{C}$ cells conducting at $<1.1 \mathrm{~m} / \mathrm{sec}, \mathrm{A} \delta$ at $1.1-4.2 \mathrm{~m} / \mathrm{sec}$, and $\mathrm{A} \alpha / \beta$ at $>4.2$ $\mathrm{m} / \mathrm{sec}$ on the basis of compound APs recorded from dorsal roots in normal animals as previously described (Djouhri et al., 1998). 


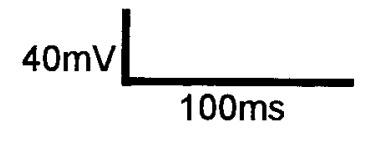

\section{A: C NOCl}

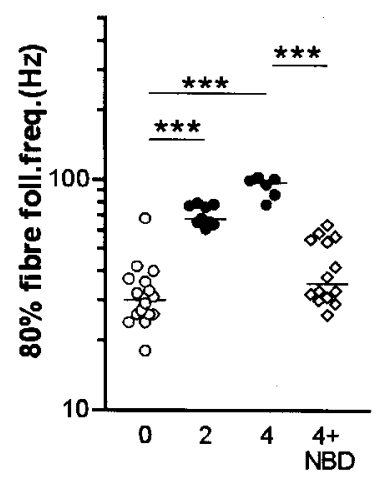

C: $\mathrm{A} \delta \mathrm{NOCl}$

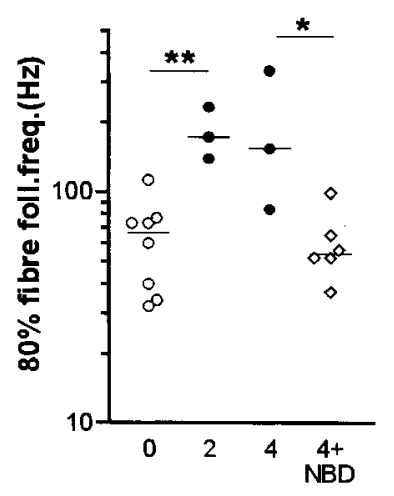

$E: A \alpha / \beta \mathrm{NOCl}$

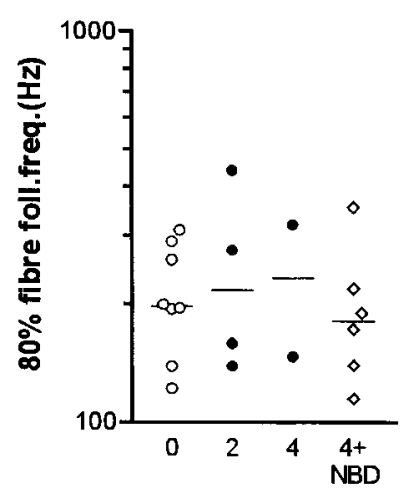

B1:C NOCI no CFA, $42 \mathrm{~Hz}$
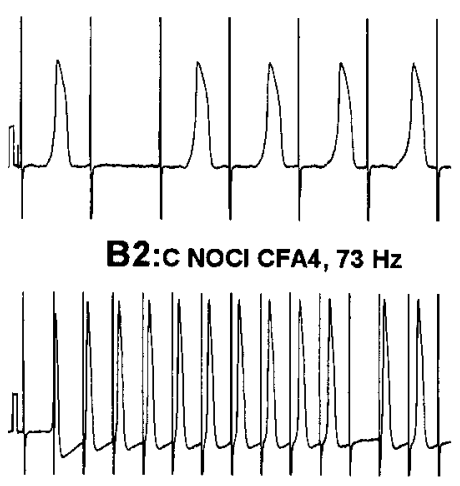

D: A $\delta$ LTM
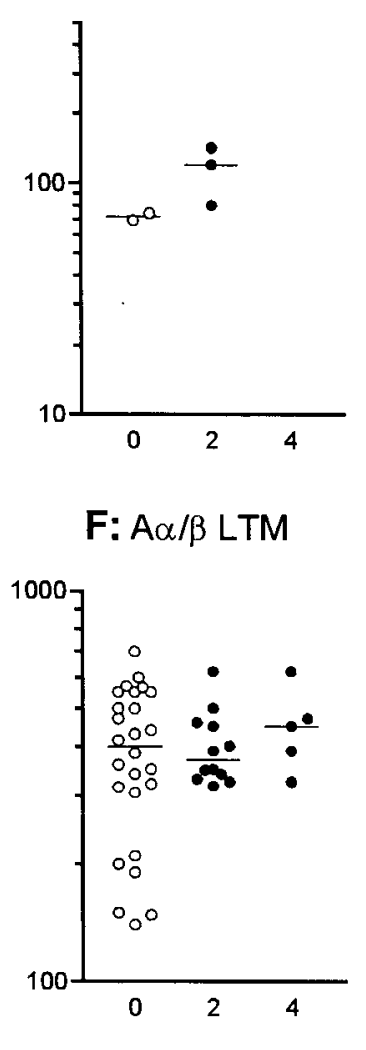

$F: A \alpha / \beta$ LTM

Figure 4. Effects of CFA and NBD treatments on fiber following frequencies. The median increase in $80 \%$ fiber following frequency (fiber $\left.\mathrm{FF}_{80 \%}\right)$ was highly significant $(p<0.0001)$ for $\mathrm{C}$ nociceptive units $(A)$ both at 2 and $4 \mathrm{~d}$ after CFA. Examples of following frequency of $\mathrm{C}$-fiber nociceptive units are shown in B1 (no CFA) and 2 (CFA4D). The fiber $\mathrm{FF}_{80 \%}$ was significantly increased in $\mathrm{A} \delta$ nociceptive units at $2 \mathrm{~d}$ post CFA $(C)$, and a nonsignificant increase remains at $4 \mathrm{~d}$. There were not enough data points for comparison in the A $\delta$ LTM units $(D)$. There was no significant change in $\mathrm{A} \alpha / \beta$-fiber nociceptive units $(E)$ or in $A \alpha / \beta$-fiber LTM units $(F)$. The abbreviation 0 means no treatment (normal); 2 means CFA2D animals; 4 means CFA4D animals, and $4+N B D$ means neurons from animals treated with CFA4D plus NBD. Medians are indicated by horizontal lines. Levels of significance between different groups are indicated by horizontal lines connecting appropriate groups and asterisks (see legend to Fig. 2). Statistics were as described for Figure 3.
The values of the CVs are relatively low because of a number of factors discussed in our previous papers (Lawson et al., 1997; Djouhri and Lawson, 1999, 2001). For the reasons discussed previously (Djouhri and Lawson, 1999), we chose the same boundaries between CV groups for all groups of animals, despite a general upward shift in CV of nociceptive neurons after CFA (Djouhri and Lawson, 2001).

The present study was intentionally biased toward nociceptive units by rejecting all $\mathrm{A} \alpha / \beta$ LTM units during recording sessions in animals $1 \mathrm{~d}$ after CFA (CFA1D) and some $\mathrm{A} \alpha / \beta$ LTM units from CFA2D and CFA4D and CFA plus NBD animals. A total of 395 nociceptive units, 81 unresponsive, and 179 LTM units were analyzed. As previously suggested (Djouhri and Lawson, 1999), the high proportion of $\mathrm{A} \alpha / \beta$ nociceptive neurons may be influenced by the greater ease of recording from neurons with larger somata. Nevertheless, substantial numbers of $\mathrm{A} \alpha / \beta$ nociceptive units were also reported in previous studies of primary afferents in vivo (Lynn and Carpenter, 1982; Ritter and Mendell, 1992; Lawson et al., 1997; Djouhri et al., 1998; Djouhri and Lawson, 1999).

\section{Effect of CFA and NGF sequestration on electrophysiological variables \\ Action potential variables}

Some of the 0 and post CFA data (2-4 d) were included in a previous publication (Djouhri and Lawson, 1999). Much additional data have enabled us to extend our previous comparisons between normal and CFA-treated animals (Djouhri and Lawson, 1999) and to examine changes 1, 2, and 4 d after CFA. These changes confirm those previous findings with the following exception. Previously in $\mathrm{C}$-fiber nociceptive units we found no significant difference between median $\mathrm{AHP}_{80}$ values $2-4 \mathrm{~d}$ after CFA (Djouhri and Lawson, 1999). In the present study, with twice the number of units, evaluation of these units at 2 and $4 \mathrm{~d}$ separately revealed a significant decrease in $\mathrm{AHP}_{80}$ duration at $4 \mathrm{~d}$.

The time course and NGF dependence of the significant changes in somatic AP and AHP variables after CFA over $4 \mathrm{~d}$ are shown, with the distribution of the data, in Figure 3. The changes in median values of variables from all three CV groups of nociceptive units are summarized in Figure 5. All of the significant changes in the variables except AP fall time (C fiber units) were incomplete $1 \mathrm{~d}$ after CFA and in most cases were slightly greater at $4 \mathrm{~d}$ than at $2 \mathrm{~d}$, indicating that at $4 \mathrm{~d}$ a peak or plateau was probably being approached.

Reversal or prevention of the changes seen in AP duration in $\mathrm{C}$ - and $\mathrm{A} \delta$-fiber nociceptive units and of the AP rise and fall times for $\mathrm{C}$ fiber nociceptive neurons at $4 \mathrm{~d}$ occurred after NGF sequestration indicating a likely NGF dependence (Figs. 3, 5). In contrast, the reductions in AHP duration in nociceptive neurons were not reversed (Figs. 3, 5), indicating a lack of NGF dependence. Indeed the extent of the change in AHP duration was increased after NBD in $\mathrm{C}$ - and $\mathrm{A} \delta$-fiber nociceptive units. This may have been attributable to the larger number of injections in each site (a total of four for the CFA plus NBD treatment compared with one for the CFA treatment alone), leading to a greater local inflammatory response.

In addition to those variables illustrated in Figure 3, there were also significant changes in the medians of other AP variables. For C-fiber nociceptive units, these included (Fig. 5) significant decreases in the medians of AP rise time (APRT) and AP fall time 

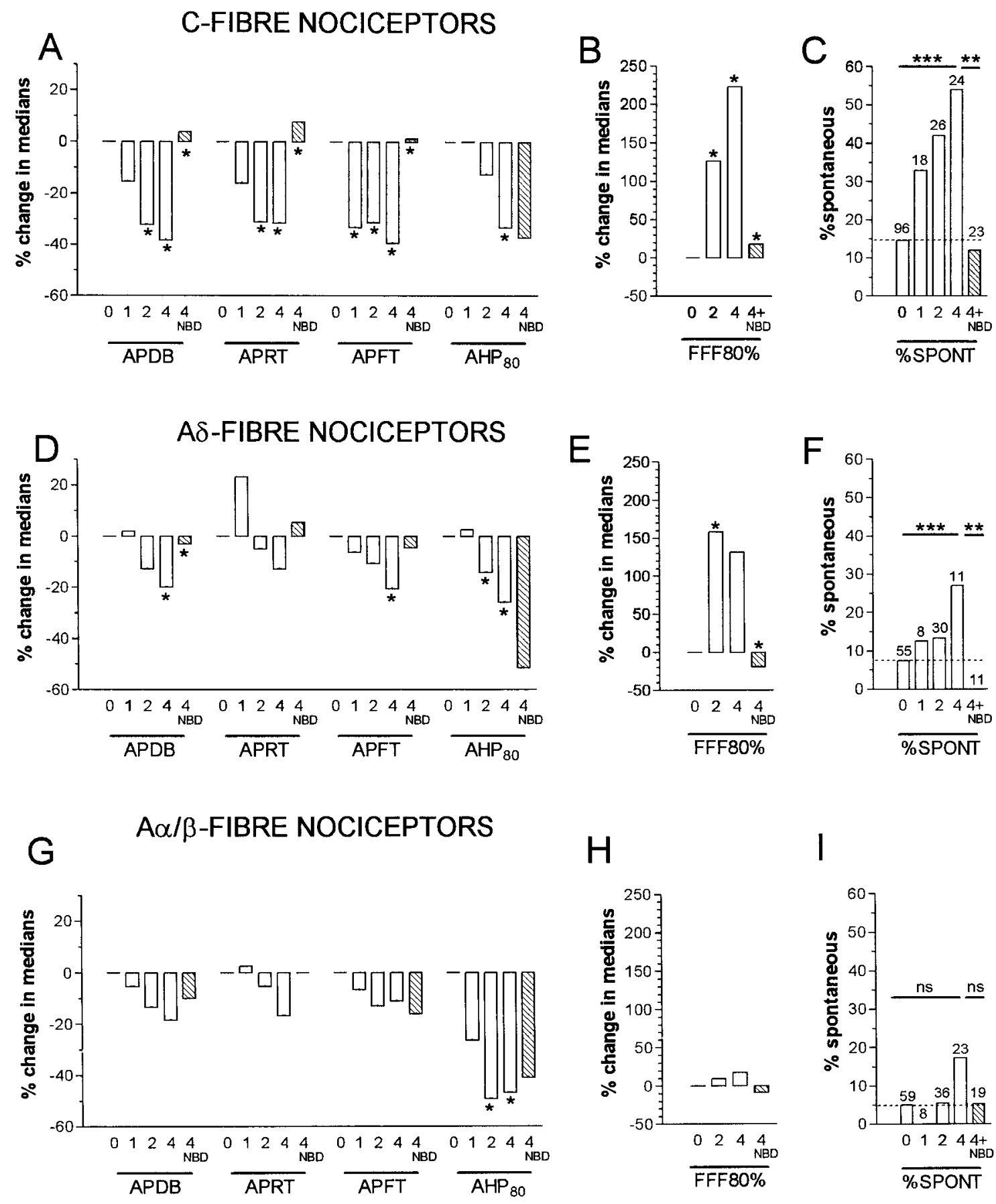

Figure 5. Summary of time course of CFA and of NGF sequestration effects on AP variables, $\mathrm{FFF}_{80 \%}$ and spontaneous activity in nociceptive units. $A-C$ show data for $\mathrm{C}$-fiber units; $D-F$ for A $\delta$-fiber units; and $G-I$ for A $\alpha / \beta$-fiber units. Throughout, 0 means no CFA treatment; 1,2 , and 4 mean 1,2 or $4 \mathrm{~d}$ after CFA, and $4+N B D$ is $4 \mathrm{~d}$ after CFA plus NBD treatment. $A, B, D, E, G$, and $H$ show summaries of changes in medians relative to the median value at 0 (no CFA treatment). A single asterisk above a 1,2, or $4 \mathrm{~d}$ column indicated a significant difference compared with untreated (0), and a single asterisk above the 4 NBD column indicated a significant difference between this and the 4 (days) column (statistical tests were as for Fig. 3 but in this summary, an asterisk indicates all $p$ values $<0.05$, detailed $p$ values in Fig. 3 and Results). $C, F$, and $I$ show the incidence of spontaneous activity in $C$-, A $\delta$-, and $\mathrm{A} \alpha / \beta$-fiber nociceptive units. A $\chi^{2}$ test for trend was performed on a $2 \times 4$ contingency table of the $0,1,2$, and $4 \mathrm{~d}$ incidences. A $\chi^{2}$ test on a $2 \times 2$ contingency table was used to compare values in the 4 with those in the $4+N B D$ columns. For these graphs only, ${ }^{* *} p<0.01$ and ${ }^{* * *} p<0.001$.

(APFT) from normal median values of 2.38 and $3.0 \mathrm{msec}$, respectively. Significant increases were also seen in: maximum rate of fall (MRF) at $2 \mathrm{~d}$ (median, $178 \mathrm{~V} / \mathrm{sec} ; p<0.001)$ and at $4 \mathrm{~d}$ (median, $165 \mathrm{~V} / \mathrm{sec} ; p<0.01$ ) from normal values of $129 \mathrm{~V} / \mathrm{sec}$ and in $\mathrm{CV}$ at $2 \mathrm{~d}$ (median, $0.51 \mathrm{~m} / \mathrm{sec} ; p<0.01$ ) and at $4 \mathrm{~d}$ (median, $0.6 \mathrm{~m} / \mathrm{sec} ; p<0.001$ ) compared with normal CV (median, $0.37 \mathrm{~m} / \mathrm{sec}$ ). In addition to AP duration at base (APDB), the changes in APRT and APFT (Fig. 5), MRF, and CV were also reversed by NBD treatment $(p<0.05)$. There were also significant increases in maximum rate of rise (MRR) from normal 
(median, $226 \mathrm{~V} / \mathrm{sec})$ to $2 \mathrm{~d}(283 \mathrm{~V} / \mathrm{sec} ; p<0.05)$ but not $4 \mathrm{~d}(266$ $\mathrm{V} / \mathrm{sec})$. Similarly the median AHP depth to $E_{\mathrm{m}}$ increased from normal $(7.2 \mathrm{mV})$ to $2 \mathrm{~d}(11.6 \mathrm{mV} ; p<0.05)$ but not to $4 \mathrm{~d}(9.9$ $\mathrm{mV})$. These increases were reversed by NBD treatment $(p<$ $0.05)$. No significant alterations in $E_{\mathrm{m}}$, AP overshoot, AP amplitude, or AHP depth measured to $0 \mathrm{mV}$ were seen at any time after CFA treatment in C-fiber nociceptive units. Apart from APDB and $\mathrm{AHP}_{80}$, the only significant change in the above variables in $\mathrm{A} \delta$-nociceptive neurons was in the median APFT from the normal (median, $1.51 \mathrm{msec}$ ) at $4 \mathrm{~d}$ but not $2 \mathrm{~d}$ (Fig. 5). This decrease was reversed by NBD treatment (Fig. 5). Apart from $\mathrm{AHP}_{80}$, none of the above variables were altered in $\mathrm{A} \alpha / \beta$ nociceptive neurons.

It is possible that treatment with CFA or NBD did not affect all the sites on the leg equally. The access of these agents to the nociceptive terminals may vary, depending on the depth of the receptive field in the tissue and its distance from the injection sites. However, the lack of significant difference in medians of AP and AHP variables between $\mathrm{C}$-fiber units with receptive fields on or near the two sites of injection and those with receptive fields further from the injection sites indicates that effects of CFA2D and CFA4D and CFA4D plus NBD were not markedly affected by the distance from the injection site within the inflamed area (leg). However, the level of active trkA (NGF receptor) on a nociceptive terminal is likely to have influenced the extent of any NGF effect.

Because of the lack of significant changes in the medians of AP and AHP variables illustrated in Figure $1 A$ between LTM units (C, A $\delta$-and $\mathrm{A} \alpha / \beta$-fiber) recorded from control and CFA (2-4 d)-treated animals as previously reported (Djouhri and Lawson, 1999), the effect of sequestering NGF with NBD was not tested on their responses. There were also no significant changes in the medians of AP or AHP durations in unresponsive $\mathrm{C}-$-, $\mathrm{A} \delta$-, and $\mathrm{A} \alpha / \beta$-fiber units from untreated animals and animals 2 or $4 \mathrm{~d}$ after CFA treatment (data not shown) (but see Djouhri and Lawson, 1999); however, some previously unresponsive neurons may have been sensitized after CFA treatment and have become classified as nociceptive neurons (Djouhri and Lawson, 1999).

\section{Following frequency}

The $80 \%$ fiber following frequencies $\left(\mathrm{FFF}_{80 \%}\right)$ of 73 nociceptive units were examined and are displayed in Figure 4. C-fiber nociceptive units showed a significant increase in median $\mathrm{FFF}_{80 \%}$ both 2 and $4 \mathrm{~d}$ after CFA compared with control values (see examples in Fig. $1 D$ ); this was reversed and/or prevented by NBD treatment (Fig. 4A). In Figure 4, $B 1$ and B2, typical examples of intracellular recordings in $\mathrm{C}$-nociceptive units illustrate the greater following frequency in a CFA4D unit compared with that in an untreated animal. In $\mathrm{A} \delta$ nociceptive units, the median $\mathrm{FFF}_{80 \%}$ was significantly higher than in untreated animals at 2 after CFA and maintained at $4 \mathrm{~d}$; this increase was again reversed or prevented by NBD treatment (Fig. $4 C$ ). There were no clear changes in $\mathrm{FFF}_{80 \%}$ in $\mathrm{A} \alpha / \beta$-fiber nociceptive units (Fig. 4E) despite the significantly decreased $\mathrm{AHP}_{80 \%}$ duration in this group of nociceptive units (Fig. 3). A summary of changes in the median values of $\mathrm{FFF}_{80 \%}$ is included in Figure $5 B, E$, and $H$.

In $\mathrm{C}$ - and $\mathrm{A} \delta$-fiber nociceptive units with a full-sized intracellularly recorded $\mathrm{AP}$, the soma $\mathrm{FF}_{80 \%}$ was also calculated for normal units and for units at 2 and $4 \mathrm{~d}$ after CFA combined. In $\mathrm{C}$-fiber nociceptors the median soma $\mathrm{FF}_{80 \%}$ was significantly increased (Mann-Whitney $U$ test) after CFA compared with normal (26, $n=11 ; 80, n=8$, respectively; $p<0.005)$, but the median ratio of fiber $\left(\mathrm{FFF}_{80 \%}\right)$ to soma $\mathrm{FF}_{80 \%}$ in these neurons was unchanged $[1$, range $1-5$ (normal); 1 , range $1-2.7$ (CFA); $p>$ $0.5]$. In contrast, in $\mathrm{A} \delta$-nociceptors, the median soma $\mathrm{FF}_{80 \%}$ was unchanged after CFA [40, $n=7$ (normal); 65, $n=5$ (CFA); $p<$ 0.4 , but the above ratio was increased after CFA from 1 in $7 / 7$ units normally to $>1$ in $4 / 5$ units after CFA (median, 3.5; range, 1-5.6).

The increased following frequencies of nociceptive dorsal root fibers during inflammation were therefore accompanied in $\mathrm{C}$ - but not $\mathrm{A} \delta$-units by an equivalent increase in soma following frequencies. Thus, the soma could not follow the increased fiber firing rate in $\mathrm{A} \delta$-units, although it could in $\mathrm{C}$-fiber units. It seems unlikely that the A $\delta$-dorsal root fibers would be similarly limited in their ability to follow an increase in peripheral nerve firing rates during inflammation, because (1) the dorsal root can fire more rapidly than usual, and (2) spike failure is more likely to occur at a point of increased membrane surface area (as from dorsal root to initial segment, or initial segment to soma) than of decreased surface area which, judging from the decrease in CV in dorsal root compared with peripheral nerve (Waddell et al., 1989b), occurs from peripheral nerve to dorsal root. We would therefore predict that, not only in C-, but also in A-fiber nociceptors, the rate of impulse transmission into the CNS is likely to be increased.

The medians of $\mathrm{FFF}_{80 \%}$ in $\mathrm{C}$-, $\mathrm{A} \delta$ - and $\mathrm{A} \alpha / \beta$-nociceptive neurons were also compared in normal animals. The median was significantly lower in C-fiber units $(30 \mathrm{~Hz})$ than that for both $\mathrm{A} \delta$-fiber $(68 \mathrm{~Hz})$ and $\mathrm{A} \alpha / \beta$-fiber units $(97 \mathrm{~Hz})$; in addition it was significantly lower in $\mathrm{A} \delta$ - than $\mathrm{A} \alpha / \beta$-fiber nociceptive units (Fig. 4, compare $A, C, E)$.

In LTMs, no $\mathrm{FFF}_{80 \%}$ values for $\mathrm{C}$ units were obtained. Although there were not enough A $\delta$ LTM (D hair) units with $\mathrm{FFF}_{80 \%}$ data for statistical comparison (Fig. 4D), it seems possible that (1) a small increase may also occur after CFA treatment in A $\delta$ LTM units, and (2) there was no difference between the median values for A $\delta$ LTM (D hair) units and A $\delta$ nociceptive units. More data are needed to confirm these points. For the $\mathrm{A} \alpha / \beta$ units, the median value was twofold greater for LTM units than for nociceptive units. In LTM units with $\mathrm{A} \alpha / \beta$-fibers, there was no significant change in the median $\mathrm{FFF}_{80 \%} 2$ or $4 \mathrm{~d}$ after CFA (Fig. $4 F)$. None of the unresponsive units were tested for following frequency.

\section{Spontaneous activity}

Over the $4 \mathrm{~d}$ after CFA-induced hindlimb inflammation, there was a significant increase ( $\chi^{2}$ test for trend) in the incidence of $\mathrm{C}$-and $\mathrm{A} \delta$-fiber nociceptive neurons exhibiting spontaneous activity; this increase was apparent but not significant at CFA1D and greatest in CFA4D animals (Fig. 5C,F). The percentage increases in CFA4D animals compared with untreated were for $\mathrm{C}$ cells $54 \%$ from $15 \%$, A $\delta$-cells $27 \%$ from $7 \%$, and $\mathrm{A} \alpha / \beta$-cells (not significant) $17 \%$ from $5 \%$. These increases in $\mathrm{C}$ - and $\mathrm{A} \delta$ - nociceptive units were reversed or prevented by NGF sequestration (Fig. 5C,F), causing the level to remain the same as, or below, that in untreated animals. These findings are consistent with those of Stucky et al. (1999), who showed large increases in the incidence of nociceptive $\mathrm{C}$-and $\mathrm{A} \delta$-fibers with ongoing activity in transgenic mice overexpressing NGF. Because no significant change in our incidence from normal to $1 \mathrm{~d}$ (a $2 \times 2$ contingency table and $\chi^{2}$ test), these data are also consistent with those of Lewin et al. 


\begin{tabular}{|c|c|c|c|c|c|c|}
\hline & & & \multirow{2}{*}{\multicolumn{2}{|c|}{ SPONT }} & \multirow[b]{2}{*}{ NOT SPONT } & \multirow{2}{*}{$\begin{array}{c}\text { SPONT VS } \\
\text { NOT SPONT }\end{array}$} \\
\hline & & & & & & \\
\hline \multicolumn{2}{|l|}{ AP Variables } & $\mathrm{N}$ & Median (25-75\%) & $\mathrm{N}$ & Median (25-75\%) & $\mathrm{P}$ \\
\hline \multirow[t]{2}{*}{ APDB (ms) } & NORMAL & 10 & $7.8(5.8-16.9)$ & 64 & $5.2(3.7-6.4)$ & $* *$ \\
\hline & $\mathrm{CFA} 2+4$ & 21 & $3.7(3.2-4.7)$ & 15 & $3.2(2.7-3.7)$ & * \\
\hline \multirow[t]{2}{*}{ APDO (ms) } & NORMAL & 10 & $2.3(1.7-4.4)$ & 64 & $1.8(1.4-2.1)$ & * \\
\hline & $\mathrm{CFA} 2+4$ & 21 & $1.4(1.3-1.9)$ & 15 & $1.3(0.9-1.4)$ & * \\
\hline \multirow[t]{2}{*}{ AP RT (ms) } & NORMAL & 10 & $2.8(2.1-3.5)$ & 64 & $2.3(1.6-2.8)$ & $(*)$ \\
\hline & $\mathrm{CFA} 2+4$ & 21 & $1.9(1.4-2.1)$ & 15 & $1.4(1.0-1.8)$ & * \\
\hline \multirow[t]{2}{*}{ AP FT (ms) } & NORMAL & 10 & $5.9(3.2-13.3)$ & 64 & $2.8(1.9-3.5)$ & $\star \star \star$ \\
\hline & $\mathrm{CFA} 2+4$ & 21 & $2.0(1.7-2.8)$ & 15 & $1.7(1.6-1.9)$ & * \\
\hline \multirow[t]{2}{*}{ AP height (mV) } & NORMAL & 10 & $58.4(49-65)$ & 64 & $65.7(57-73)$ & * \\
\hline & $\mathrm{CFA} 2+4$ & 21 & $66.5(59-79)$ & 15 & $70.5(59-76)$ & ns \\
\hline AHP depth from 0 & NORMAL & 10 & $42.4(40-56)$ & 51 & $54.3(47-71)$ & * \\
\hline$(\mathrm{mV})$ & $\mathrm{CFA} 2+4$ & 21 & $52.1(49-77)$ & 15 & $55.7(53-64)$ & ns \\
\hline \multirow[t]{2}{*}{$\mathrm{Em}(\mathrm{mV})$} & NORMAL & 10 & $40.3(39-50)$ & 51 & $44.2(41-51)$ & ns \\
\hline & CFA2+4 & 21 & $43.5(36-52)$ & 15 & $44.1(40-50)$ & ns \\
\hline
\end{tabular}

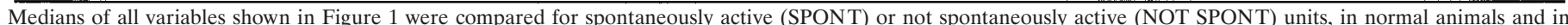

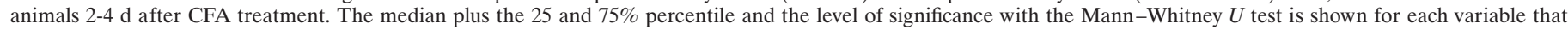
showed any significant difference between SPONT and NOT SPONT groups, in addition $E_{\mathrm{m}}$ were included. $P$ value asterisks as on Figure 3.

(1993, 1994), who showed no increase in nociceptive C and A $\delta$-dorsal root fibers $1 \mathrm{~d}$ after NGF.

With regard to LTM units, there were too few $\mathrm{C}$ units for any statistical test on incidence of spontaneous activity (data not shown), the number of LTM (D hair) units showing ongoing activity increased from $20 \%$ (normal, $n=18$ ) to $33 \%$ (CFA2D, $n=15$; CFA4D, $n=6$ ), but this was not significant ( $\chi^{2}$ test). For $\mathrm{A} \alpha / \beta$-LTM units, the percentages of cutaneous units showing spontaneous activity $2 \mathrm{~d}(7 \% ; n=46)$ or $4 \mathrm{~d}(0 \% ; n=7)$ after CFA were not significantly different from normal $(7 \% ; n=96)$. Similarly, the percentage of deep (muscle spindle) LTM units with spontaneous activity in normal (94\%; $n=53)$ was not significantly different from that $2(77 \% ; n=22)$ or $4 \mathrm{~d}(88 \% ; n=$ 8) after CFA treatment. The high incidence of spontaneous activity in muscle spindle (MS) units probably results from the leg muscles being stretched to hold the paw for receptive field examination. Because spontaneous activity was one of the criteria used to identify MS units, we cannot be certain that there was no change in the incidence of MS units with spontaneous activity. None of the unresponsive units showed spontaneous activity.
AP variables in units with and without spontaneous activity

The variables (illustrated in Fig. $1 A$ ) of $\mathrm{C}$ - and A $\delta$-fiber nociceptive units with spontaneous activity were compared with those without. For the A $\delta$ units, none of these variables nor $\mathrm{CV}$ differed significantly. In contrast, differences in several of these variables were apparent in $\mathrm{C}$-fiber units. The distributions of AP durations and AHP depths are shown in Figure 6. Both normally and after CFA treatment, the spontaneously active units tended to have longer median AP durations (Fig. 6A), including longer action potential duration at zero millivolts (APD0), APRT, and APFT (Table 1). Most of these differences were significant (see Table 1 for levels of significance). In addition they had AHPs with maximum depths that were less negative than units without spontaneous activity (Fig. 6B) and APs with a greater height; these differences were both significant normally but not after CFA (Table 1). Thus, in general, units with slower AP kinetics were more likely to show spontaneous activity. This was initially surprising, because after CFA the AP duration in C-fiber nociceptive neurons was reduced, but the incidence of spontaneously 
A
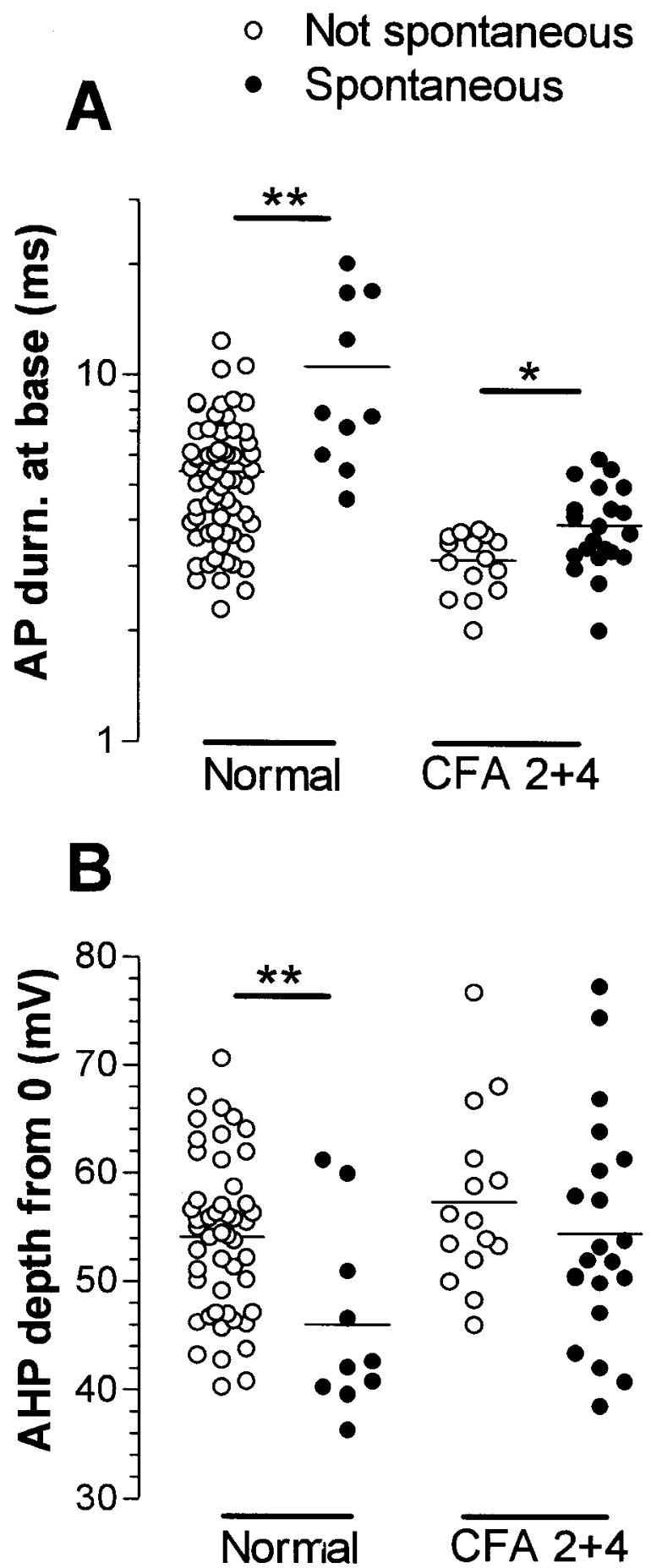

Figure 6. Scattergrams to illustrate properties of spontaneously active C-fiber nociceptive units. Somatic AP durations and AHP depths in $\mathrm{C}$-fiber units that did (filled circles) or did not (open circles) show spontaneous activity are plotted. Their medians were compared with the Mann-Whitney $U$ test, both for units from untreated and from CFAtreated $(2-4 \mathrm{~d})$ animals. The AHP depth was measured from $0 \mathrm{mV}$ (Fig. $1,9) . p$ value asterisks as in Figure 3.

active units increased. However, it can be seen in Figure 6 and Table 1 that after CFA both groups had shorter duration APs than the nonspontaneously active units normally. This CFArelated decrease in AP duration was proportionally larger (53\% for spontaneous units and $38 \%$ for nonspontaneously active units) than the difference in AP duration between units with and without spontaneous activity (33\% in normal and $14 \%$ after CFA). There was no significant difference $(p>0.05)$ after CFA in $\mathrm{FFF}_{80 \%}$ of $\mathrm{C}$ nociceptive units with (median, $79 ; n=7$ ) and without (median, $78 ; n=8$ ) spontaneous activity. Units that are normally spontaneously active may be a particular subgroup of neurons that respond to changes in the internal environment (e.g., a subset of homeostatic afferents); the membrane receptors that they express, or the ion channel complement in their membranes, may dictate their spontaneous activity.

\section{DISCUSSION}

The present study shows that in nociceptive neurons the inflammation-induced decreases in AP and AHP duration and the increases (in $\mathrm{C}$ - and $\mathrm{A} \delta$-fiber units) in both fiber following frequency $\left(\mathrm{FFF}_{80 \%}\right)$ and percentage of units with spontaneous activity were incomplete 1 or $2 \mathrm{~d}$ after CFA, progressing further between 1-2 and/or 2-4 d after CFA. NGF sequestration studies showed that all these changes except AHP duration were NGF-dependent.

\section{Site and time course of change in action potential variables}

The delayed onset of these changes and distance of our recordings in DRGs from the peripheral terminals make it unlikely that these changes reflect acute local sensitization of peripheral terminals. These factors suggest that the changes result from (1) retrograde transport of a factor or factors such as NGF from periphery to neuronal soma and/or (2) a consequent alteration in neuronal gene expression affecting membrane properties of the entire DRG neuron. Similar effects on sympathetic neurons that express trkA cannot be excluded, because these may indirectly affect DRG neuronal function. However, whether the NGFdependent changes in DRG neurons are direct or indirect cannot be determined from the present experiments.

\section{Fiber following frequency $\left(\mathrm{FFF}_{\mathbf{8 0}}\right.$ )}

The novel findings of inflammation-induced a twofold to threefold increase in $\mathrm{FFF}_{80 \%}$ in $\mathrm{C}$ - and $\mathrm{A} \delta$-nociceptors accompanies decreased somatic AP and AHP durations (Djouhri and Lawson, 1999). The ability of the C-fiber nociceptive somata to follow faithfully the increased fiber firing rates during inflammation implies no increase in spike failure at the $\mathrm{T}$ junction, and therefore a likely increased impulse traffic via peripheral nerve to dorsal root and CNS thus contributing to inflammatory hyperalgesia. This may also be the case for A $\delta$ nociceptive fibers despite failure of somata to follow the faster firing frequencies (see Results).

\section{Spontaneous activity}

Because the inflammation induced increase in spontaneous activity (reported here for the first time) was incomplete $1 \mathrm{~d}$ after CFA, its cause is unlikely to be the same as that of short-term (3-11 hr) increases after carrageenan treatment in rat and cat (Koltzenburg et al., 1999; Xu et al., 2000) possibly resulting from acute sensitization of nociceptive terminals. Unlike the shortterm increase in spontaneous activity thought to be generated in peripheral fibers (Xu et al., 2000), the origin of the slower onset 
in spontaneous activity described here is unknown. Its slow onset and NGF dependence may indicate NGF-dependent alterations in protein expression, of e.g., ion channel proteins or membrane receptors, that lead to decreased thresholds or unstable membrane properties.

\section{Possible ionic mechanisms}

Possible ionic mechanisms underlying changes in AP and AHP durations in nociceptive DRG neurons during inflammation were discussed previously (Djouhri and Lawson, 1999). In normal small DRG neurons, the TTX-resistant $\mathrm{Na}^{+}$current responsible for long-duration APs (probably C-fiber nociceptive units, see Djouhri et al., 1998) has slower kinetics and higher activation thresholds than TTX-sensitive (TTXS) $\mathrm{Na}^{+}$currents (Elliott and Elliott, 1993). The latter are thought to be the properties of the sensory nerve specific (SNS)/peripheral nerve 3 (PN3) $\alpha$ subunit (Akopian et al., 1999). Whether or not SNS expression is altered during inflammation (see Okuse et al., 1997; Tanaka et al., 1998), there is evidence that NGF may upregulate TTXS Na ${ }^{+}$currents and channels (e.g., PN1, $\alpha$ I and $\alpha$ II and $\beta 1$ ) (Fjell et al., 1999b; Gould, III et al., 2000). Especially in C-fiber nociceptors, this NGF-dependent upregulation could increase the current density, AP kinetics of nociceptors and CV and may lower AP thresholds leading to reduced withdrawal thresholds (this paper and see Woolf et al., 1994; Djouhri and Lawson, 2001).

Increased AP kinetics may contribute to increased $\mathrm{FFF}_{80 \%}$, especially in units with normally long-duration APs (C-fiber nociceptive units). Decreased AP threshold could also contribute to increased $\mathrm{FFF}_{80 \%}$, as well as to spontaneous activity by increasing the likelihood of firing and decreasing any delay during depolarization. $I_{\mathrm{h}}$ (hyperpolarization activated current), normally present in most large and some small DRG neurons (Scroggs et al., 1994), has a depolarizing effect, and its block reduces the likelihood of firing (Wang et al., 1997). Increased $I_{\mathrm{h}}$ could therefore contribute to spontaneous firing (Akasu et al., 1993), but its NGF dependence is unknown. A TTXR-persistent current in DRG neurons, activated around $E_{\mathrm{m}}$ or at more hyperpolarized potentials, also tends to depolarize the membrane (Cummins et al., 1999). The $\mathrm{NaN} \mathrm{Na}^{+}$channel subunit, thought to be responsible for this current, is upregulated in DRG neurons in NGFoverexpressing mice (Fjell et al., 1999b) and thus may also be upregulated during inflammation. However, whether a depolarizing effect of increased $I_{\mathrm{h}}$ or TTXR-persistent current would increase or decrease spontaneous activity may depend on the inactivation properties of the particular complement of $\mathrm{Na}^{+}$ channels present, which in turn is probably altered during inflammation.

\section{Properties of units with spontaneous activity}

Interestingly, nociceptive units with spontaneous activity had longer duration APs than those without, both normally and after CFA. Reduction of a $\mathrm{K}^{+}$current that normally shortens the AP duration and prolongs the refractory period, thus suppressing subsequent AP generation, could be responsible for the broader APs in these units. A type of $\mathrm{Ca}^{2+}$-activated $\mathrm{K}^{+}\left(I_{\mathrm{KCa}}\right)$ current, known as $B_{\mathrm{KCa}}$ (big conductance) has these effects in cultured small DRG neurons (Scholz et al., 1998). Furthermore, a decrease in the rapidly activating outward $\mathrm{K}^{+}$current $\left(I_{\mathrm{A}}\right)$ has been shown to broaden the AP in A-fiber DRG neurons, as well as inducing spontaneous activity and increased soma following frequency (Waddell et al., 1989a). Indeed suppression of $I_{\mathrm{A}}$ has been suggested to underlie the increased firing frequency of rat bladder afferent $\mathrm{C}$-fiber neurons after chronic bladder inflammation (Yoshimura and De Groat, 1999). Therefore, relatively less $I_{\mathrm{BKCa}}$ and $I_{\mathrm{A}}$, for example, in spontaneously active units could explain both this activity and the broader APs. It may be that the relatively large decrease in AP duration after CFA results from altered $\mathrm{Na}^{+}$ currents, and the smaller difference in AP duration between units with and without spontaneous activity results from differences in other currents such as $I_{\mathrm{BKCa}}$ or $I_{\mathrm{A}}$. This could involve altered expression or properties of e.g., $I_{\mathrm{BKCa}}$ or $I_{\mathrm{A}}$ after CFA or there may be underlying differences in these channels and currents that are revealed by altered expression of other channel types such as $\mathrm{Na}^{+}$(see above). Much more needs to be learned about the roles of these and other relevant currents [e.g., the inward rectifier $\mathrm{K}^{+}$ $\left(I_{\mathrm{KIR}}\right)$ or $\mathrm{Ca}^{2+}$ channels] in DRG neurons both normally and after CFA before their contributions to inflammation-induced changes can be elucidated.

The similarity of $\mathrm{FFF}_{80 \%}$ in spontaneously active to not spontaneously active $\mathrm{C}$ - nociceptive neurons after CFA is indicative of different mechanisms underlying the increases in spontaneous firing and following frequency.

\section{NGF dependence}

These studies support previous studies showing a lack of NGF effect on AHP duration in rat A-fiber nociceptors (Ritter and Mendell, 1992). Peripheral axotomy, which should decrease NGF availability in the soma, did not affect AHP duration in rat DRG neurons (Kim et al., 1998; Stebbing et al., 1999). Because of the NGF dependence of the firing frequency and spontaneous activity but not of the reduced $\mathrm{AHP}_{80}$ duration, the most influential currents in altering firing frequency and spontaneous activity are unlikely to make a significant contribution to the $\mathrm{AHP}_{80}$ duration. The $\mathrm{AHP}_{80}$ is likely to be dominated by the longest duration $\mathrm{K}^{+}$ current present; in nociceptors the activity of this channel (possibly a type of $I_{\mathrm{KCa}}$ see Sah, 1996) appears unlikely to be NGF dependent. However, we cannot exclude the possibility that $\mathrm{K}^{+}$ channels with faster kinetics (e.g., $I_{\mathrm{A}}$ ) that contribute to the AHP depth but not to the long $\mathrm{AHP}_{80}$ may be altered in an NGF dependent manner.

The inflammation-induced changes that are NGF dependent in nociceptive neurons may underlie the observations that neutralization of endogenous NGF blocked inflammation induced hyperalgesia and prevented sensitization of nociceptors (Woolf et al., 1994; McMahon et al., 1995; Koltzenburg et al., 1999). They may result from the known regulatory effects of NGF on expression of a variety of ion channel types in DRG neurons, although other neurotrophins such as GDNF may contribute to this regulation (Fjell et al., 1999a). NGF dependence has been established for certain $\mathrm{Na}^{+}$(see above) and $\mathrm{K}^{+}$(the transient $I_{\mathrm{A}}$ and the sustained $I_{\mathrm{K}}$ ) channel and currents (Everill and Kocsis, 2000), but has not been studied for some of the channel types (such as those responsible for $I_{\mathrm{h},} I_{\mathrm{KCa}}, I \mathrm{~K}_{(\mathrm{IR})}$ ) that could contribute to altered firing frequency or spontaneous activity seen here.

In conclusion, the finding that fundamental changes in membrane properties of nociceptive neurons during inflammation are incomplete $1 \mathrm{~d}$ after inflammation is indicative of protein synthe- 
sis and/or retrograde transport of a factor contributing to these changes. The increased spontaneous activity and firing frequency especially in C-fiber nociceptive neurons probably contribute to inflammatory hyperalgesia. The NGF dependence in C and A $\delta$ nociceptors of increased spontaneous activity and firing frequency and of decreased AP but not AHP duration and of increased $\mathrm{CV}$ in $\mathrm{C}$-fiber nociceptors, could explain the previously described NGF dependence of inflammatory hyperalgesia. Sequestration of endogenous NGF during inflammation might therefore prove useful in preventing the development of inflammatory hyperalgesia.

\section{REFERENCES}

Akasu T, Shoji S, Hasuo H (1993) Inward rectifier and low-threshold calcium currents contribute to the spontaneous firing mechanism in neurons of the rat suprachiasmatic nucleus. Pflügers Arch 425:109-116.

Akopian AN, Souslova V, England S, Okuse K, Ogata N, Ure J, Smith A, Kerr BJ, McMahon SB, Boyce S, Hill R, Stanfa LC, Dickenson AH, Wood JN (1999) The tetrodotoxin-resistant sodium channel SNS has a specialized function in pain pathways. Nat Neurosci 2:541-548.

Cummins TR, Dib-Hajj SD, Black JA, Akopian AN, Wood JN, Waxman SG (1999) A novel persistent tetrodotoxin-resistant sodium current In SNS-null and wild-type small primary sensory neurons. J Neurosci 19:RC43.

Davis BM, Lewin GR, Mendell LM, Jones ME, Albers KM (1993) Altered expression of nerve growth factor in the skin of transgenic mice leads to changes in response to mechanical stimuli. Neuroscience $56: 789-792$.

Djouhri, L, Lawson SN (1999) Changes in somatic action potential shape in guinea pig nociceptive primary afferent neurons during inflammation in vivo. J Physiol (Lond) 520:565-576.

Djouhri L, Lawson SN (2001) Increased conduction velocity of nociceptive primary afferent neurons during unilateral hindlimb inflammation in the anaesthetised guinea-pig. Neuroscience 102:669-679.

Djouhri L, Bleazard L, Lawson SN (1998) Association of somatic action potential shape with sensory receptive properties in guinea pig dorsal root ganglion neurons. J Physiol (Lond) 513:857-872.

Djouhri L, Dawbarn D, Robertson AGS, Lawson SN (1999) Inflammation induced changes in the action potential (AP) shape of C nociceptive DRG neurons are reversed by nerve growth factor (NGF) sequestration. Soc Neurosci Abstr 25:772.8.

Dmitrieva N, McMahon SB (1996) Sensitisation of visceral afferents by nerve growth factor in the adult rat. Pain 66:87-97.

Dyck PJ, Peroutka S, Rask C, Burton E, Baker MK, Lehman KA, Gillen DA, Hokanson JL, O'Brien PC (1997) Intradermal recombinant human nerve growth factor induces pressure allodynia and lowered heatpain threshold in humans. Neurology 48:501-505.

Elliott AA, Elliott JR (1993) Characterization of TTX-sensitive and TTX-resistant sodium currents in small cells from adult rat dorsal root ganglia. J Physiol (Lond) 463:39-56.

Everill B, Kocsis JD (2000) Nerve growth factor maintains potassium conductance after nerve injury in adult cutaneous afferent dorsal root ganglion neurons. Neuroscience 100:417-422.

Fjell J, Cummins TR, Dib-Hajj SD, Fried K, Black JA, Waxman SG (1999a) Differential role of GDNF and NGF in the maintenance of two TTX-resistant sodium channels in adult DRG neurons. Brain Res Mol Brain Res 67:267-282.

Fjell J, Cummins TR, Davis BM, Albers KM, Fried K, Waxman SG, Black JA (1999b) Sodium channel expression in NGF-overexpressing transgenic mice. J Neurosci Res 57:39-47.

Gould III HJ, England JD, Liu ZP, Levinson SR (1998) Rapid sodium channel augmentation in response to inflammation induced by complete Freund's adjuvant. Brain Res 802:69-74.

Gould III HJ, Gould TN, England JD, Paul D, Liu ZP, Levinson SR (2000) A possible role for nerve growth factor in the augmentation of sodium channels in models of chronic pain. Brain Res 854:19-29.

Hargreaves K, Dubner R, Brown F, Flores C, Joris J (1988) A new and sensitive method for measuring thermal nociception in cutaneous hyperalgesia. Pain 32:77-88.

Holden PH, Asopa V, Robertson AG, Clarke AR, Tyler S, Bennett GS, Brain SD, Wilcock GK, Allen SJ, Smith SK, Dawbarn D (1997) Immunoglobulin-like domains define the nerve growth factor binding site of the TrkA receptor. Nat Biotechnol 15:668-672.
Kim YI, Na HS, Kim SH, Han HC, Yoon YW, Sung B, Nam HJ, Shin SL, Hong SK (1998) Cell type-specific changes of the membrane properties of peripherally-axotomized dorsal root ganglion neurons in a rat model of neuropathic pain. Neuroscience 86:301-309.

Koltzenburg M, Bennett DL, Shelton DL, McMahon SB (1999) Neutralization of endogenous NGF prevents the sensitization of nociceptors supplying inflamed skin. Eur J Neurosci 11:1698-1704.

Lawson SN, Crepps BA, Perl ER (1997) Correlation of Substance P-like immunoreactivity with sensory receptor type in guinea pig primary afferent neurones. J Physiol (Lond) 505:177-191.

Lewin GR, Ritter AM, Mendell LM (1993) Nerve growth factorinduced hyperalgesia in the neonatal and adult rat. $\mathrm{J}$ Neurosci 13:2136-2148.

Lewin GR, Rueff A, Mendell LM (1994) Peripheral and central mechanisms of NGF-induced hyperalgesia. Eur J Neurosci 6:1903-1912.

Luscher C, Streit J, Lipp P, Luscher H-R (1994) Action potential propagation through embryonic dorsal root ganglion cells in culture. II Decrease of conduction reliability during repetitive stimulation. J Neurophysiol 72:634-643.

Lynn B, Carpenter SE (1982) Primary afferent units from the hairy skin of the rat hind limb. Brain Res 238:29-43.

McMahon SB, Bennett DL, Priestley JV, Shelton DL (1995) The biological effects of endogenous nerve growth factor on adult sensory neurons revealed by a trkA-IgG fusion molecule. Nat Med 1:774-780.

Millan MJ (1999) The induction of pain: an integrative review. Prog Neurobiol 57:1-164.

Murphy M, Reid K, Brown MA, Bartlett PF (1993) Involvement of leukemia inhibitory factor and nerve growth factor in the development of dorsal root ganglion neurons. Development 117:1173-1182.

Nordin M, Nystrom B, Wallin U, Hagbarth KE (1984) Ectopic sensory discharges and paresthesiae in patients with disorders of peripheral nerves, dorsal roots and dorsal columns. Pain 20:231-245.

Okuse K, Chaplan SR, McMahon SB, Luo ZD, Calcutt NA, Scott BP, Akopian AN, Wood JN (1997) Regulation of expression of the sensory neuron-specific sodium channel SNS in inflammatory and neuropathic pain. Mol Cell Neurosci 10:196-207.

Oyelese AA, Rizzo MA, Waxman SG, Kocsis JD (1997) Differential effects of NGF and BDNF on axotomy-induced changes in GABA(A)receptor-mediated conductance and sodium currents in cutaneous afferent neurons. J Neurophysiol 78:31-42.

Perez P, Coll PM, Hempstead BL, Martin-Zanca D, Chao MV (1995) NGF binding to the trk tyrosine kinase receptor requires the extracellular immunoglobulin-like domains. Mol Cell Neurosci 6:97-105.

Petty BG, Cornblath DR, Adornato BT, Chaudhry V, Flexner C, Wachsman M, Sinicropi D, Burton LE, Peroutka SJ (1994) The effect of systemically administered recombinant human nerve growth factor in healthy human subjects. Ann Neurol 36:244-246.

Ritter AM, Mendell LM (1992) Somal membrane properties of physiologically identified sensory neurons in the rat: effects of nerve growth factor. J Neurophysiol 68:2033-2041.

Robertson AG, Banfield MJ, Allen SJ, Dando JA, Mason GG, Tyler SJ, Bennett GS, Brain SD, Clarke AR, Naylor RL, Wilcock GK, Brady RL, Dawbarn D (2001) Identification and structure of the nerve growth factor binding site on TrkA. Biochem Biophys Res Commun 282:131-141.

Rueff A, Mendell LM (1996) Nerve growth factor NT-5 induce increased thermal sensitivity of cutaneous nociceptors in vitro. J Neurophysiol 76:3593-3596.

Sah P (1996) $\mathrm{Ca}^{2+}$-activated $\mathrm{K}^{+}$currents in neurones: types, physiological roles and modulation. Trends Neurosci 19:150-154.

Scholz A, Gruss M, Vogel W (1998) Properties and functions of calciumactivated $\mathrm{K}+$ channels in small neurones of rat dorsal root ganglion studied in a thin slice preparation. J Physiol (Lond) 513:55-69.

Scroggs RS, Todorovic SM, Anderson EG, Fox AP (1994) Variation in $\mathrm{I}(\mathrm{H}), \mathrm{I}(\mathrm{IR})$, and I(LEAK) between acutely isolated adult rat dorsal root ganglion neurons of different size. J Neurophysiol 71:271-279.

Stebbing MJ, Eschenfelder S, Habler H-J, Acosta MC, Janig W, McLachlan EM (1999) Changes in the action potential in sensory neurones after peripheral axotomy in vivo. NeuroReport 10:201-206.

Stoney Jr SD (1990) Limitations on impulse conduction at the branch point of afferent axons in frog dorsal root ganglion. Exp Brain Res 80:512-524.

Stucky CL, Koltzenburg M, Scneider M, Engle MG, Albers KM, Davis BM (1999) Overexpression of nerve growth factor in skin selectively affects the survival and functional properties of nociceptors. J Neurosci 19:8509-8516.

Tanaka M, Cummins TR, Ishikawa K, Dib-Hajj SD, Black JA, Waxman SG (1998) SNS Na+ channel expression increases in dorsal root ganglion neurons in the carrageenan inflammatory pain model. NeuroReport 9:967-972.

Ultsch MH, Wiesmann C, Simmons LC, Henrich J, Yang M, Reilly D, Bass SH, de Vos AM (1999) Crystal structures of the neurotrophinbinding domain of TrkA, TrkB and TrkC. J Mol Biol 290:149-159. 
Urfer R, Tsoulfas P, O'Connell L, Shelton DL, Parada LF, Presta LG (1995) An immunoglobulin-like domain determines the specificity of neurotrophin receptors. EMBO J 14:2795-2805.

Waddell PJ, McCarthy PW, Reeh PW (1989a) The effect of 4-aminopyridine on action potential shape and firing pattern of rat dorsal root ganglion neurones. Pflügers Arch 414:S131-S132.

Waddell PJ, Lawson SN, McCarthy PW (1989b) Conduction velocity changes along the processes of rat primary sensory neurons, Neuroscience 30:577-584.

Wang Z, Van den Berg RJ, Ypey DL (1997) Hyperpolarization-activated currents in the growth cone and soma of neonatal rat dorsal root ganglion neurons in culture. J Neurophysiol 78:177-186.
Wiesmann C, Ultsch MH, Bass SH, de Vos AM (1999) Crystal structure of nerve growth factor in complex with the ligand-binding domain of the TrkA receptor. Nature 401:184-188.

Woolf CJ, SafiehGarabedian B, Ma QP, Crilly P, Winters J (1994) Nerve growth factor contributes to the generation of inflammatory sensory hypersensitivity. Neuroscience 62:327-331.

Xu GY, Huang LY, Zhao ZQ (2000) Activation of silent mechanoreceptive cat $\mathrm{C}$ and Adelta sensory neurons and their substance $\mathrm{P}$ expression following peripheral inflammation. J Physiol (Lond) 528(Pt 2):339-348. Yoshimura N, De Groat WC (1999) Increased excitability of afferent neurons innervating rat urinary bladder after chronic bladder inflammation. J Neurosci 19:4644-4653. 